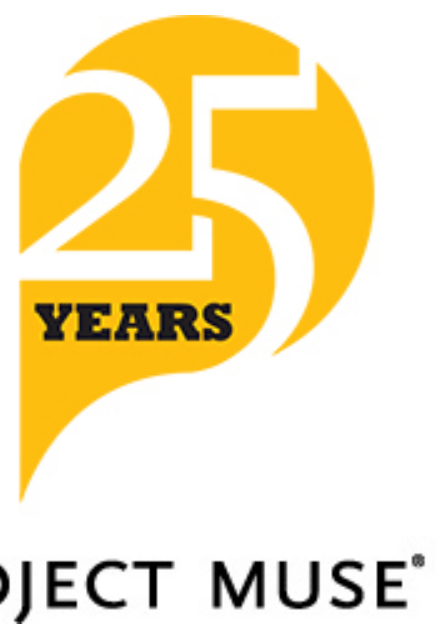

PROJECT MUSE*

Watsuji, Intentionality, and Psychopathology

Joel Krueger

Philosophy East and West, Volume 70, Number 3, July 2020, pp. 757-780 (Article)

Philosophy East and West

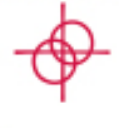

A Qwishly of

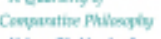

Published by University of Hawai'i Press

$\Rightarrow$ For additional information about this article https://muse.jhu.edu/article/759305 


\section{WATSUJI, INTENTIONALITY, AND PSYCHOPATHOLOGY}

\section{Joel Krueger}

Department of Sociology, Philosophy, and Anthropology,

University of Exeter

j.krueger@exeter.ac.uk

\section{Introduction}

Within recent years, there has been increased interest in the work of Tetsurō Watsuji. He is now regularly invoked in discussions of, among other things, ethics, embodiment, the self, political philosophy, environmental ethics, architectural studies, and human geography. But despite this renewed interest, there remain many underexplored areas in his work worthy of further attention. In what follows, I draw attention to one of these areas: Watsuji's discussion of intentionality.

As part of his more general discussion of embodiment, subjectivity, and intersubjectivity, Watsuji develops a rich characterization of intentionality, or the capacity of conscious states to be about things. I am here especially concerned with Watsuji's arguments for the inherently social character of intentionality. This is the idea that both the character and content of our intentional acts - which determine how the world and things in it show up as objects of experience-are deeply regulated by our sociocultural milieu or "betweenness" (aidagara), as he terms it. Accordingly, we cannot understand intentionality without considering its constitutive relation with betweenness. While provocative, this aspect of Watsuji's work has thus far received little attention.

In light of this neglect, the following discussion has two main objectives: interpretation and application (the former will receive more attention than the latter). First, I unpack Watsuji's discussion of the social character of intentionality, show how it connects with his more general discussion of embodiment and betweenness, and then situate this characterization alongside phenomenological discussions of intentionality found in thinkers like Husserl, Heidegger, and Merleau-Ponty. Second, I put Watsuji's ideas to work. I argue that Watsuji's characterization of the social character of intentionality is relevant to current discussions in phenomenological psychopathology. I look especially at how it can help illuminate the character and structure of some anomalous experiences in schizophrenia in which individuals become experientially unmoored from other people and things. I argue further that this application can enrich existing attempts to connect Watsuji and psychopathology, such as those found in the work of the psychiatrist Bin Kimura. 
To be clear, I am not going to spend a lot of time evaluating the success of Watsuji's arguments or considering possible objections, although I find many of his arguments compelling and will offer philosophical and empirical support for them along the way. A thorough defense is a project for another time. Instead, my primary aim is simply to bring some of these arguments to light and show their ongoing relevance to current debates. I turn to that task now.

\section{Watsuji on Intentionality and the Dynamics of Betweenness}

This is not the place for an overview of Watsuji's large corpus. ${ }^{1}$ Instead, I offer a brief summary of some of his central ideas, focusing on those most relevant for understanding his characterization of intentionality. At the heart of Watsuji's approach—particularly in Rinrigaku ("Ethics") (1996), arguably his most important work and one of only a few of his texts translated into English-is his phenomenology of aidagara, or "betweenness." For Watsuji, aidagara captures experiential and enactive dynamics that generate basic forms of embodied selfhood (Krueger 2013a; McCarthy 2011b). Nearly all his remarks in Rinrigaku about ethics, social ontology, and the self originate in some way from this notion (Shields 2009). Near the start of this text he tells us that "[t]he locus of ethical problems lies not in the consciousness of the isolated individual, but precisely in the in-betweenness of person and person" (Watsuji 1996, p. 10). So, it is important to be clear at the start about what betweenness means for Watsuji before then looking at how it connects with his characterization of intentionality.

\section{Watsuji on Betweenness}

Simply put, aidagara for Watsuji refers to the various ways that human reality is organized by dimensions and intensities of spatiality. However, this idea refers to more than the trivial observation that human beings, like other things in the world, take up space and therefore stand in determinate spatial relations with one another like trees in a forest or furniture in a room. Importantly for Watsuji, "[t]his sort of spatiality [i.e., of aidagara] is not the same as space in the world of nature"; it is, rather, lived space, "the betweenness itself of subjective human beings" (Watsuji 1996, pp. 156-157).

For Watsuji, this betweenness can take many forms: from the bodily intimacy of newborn-caregiver interactions or sexual intercourse to more encompassing forms of betweenness like emotional contagion within large groups (e.g., sporting events, political rallies), or even the ways that material infrastructures organize the flows of information, communication, and transportation that constrain opportunities for connection between individuals and communities. According to Watsuji, to be a human being is not just to exist in time-à la Heidegger, an important influence on Watsuji-but 
also in and through multiple dimensions and intensities of space. ${ }^{2}$ This spatial orientation is fundamental to our experience of self and world. As he summarizes his view here: "I regard this subjective spatiality as the essential characteristic of human beings. Without it, the systematic relationships between personalities could not be understood" (Watsuji 1996, p. 157).

Early in Rinrigaku, Watsuji tells us that aidagara implies "a living and dynamic betweenness, as a subjective interconnection of acts" (Watsuji 1996, p. 18). Already in this brief characterization, two important points are worth noting. First, aidagara for Watsuji is inextricably linked with subjectivity, the first-person perspective; we experience and live through dimensions and intensities of aidagara. Second, aidagara is tied to the dynamics of our embodied agency; it is something we play an active role in when creating and sustaining. To understand aidagara, then, we must develop a fuller picture of what it means to be an embodied subject engaging with the biological, sociocultural, and material environments that comprise our shared world.

The starting point for Watsuji's phenomenological analysis of aidagara is his discussion-echoing the analysis found in phenomenologists like Husserl, Merleau-Ponty, and Sartre-of the lived body (Krueger 2013a; McCarthy 2011a). Watsuji argues that to be an embodied, animate subject is to concretely realize betweenness; the latter is an internal principle of the self that specifies the "dual structure" of our embodiment (Watsuji 1996, p. 19). What this means is that we, as embodied beings, are hybrid entities: we realize "a dialectical unity" (p. 15) of both objective and subjective dimensions. On the one hand, we have physical bodies with properties like size, shape, color, texture, and weight. Our physical bodies are objects situated in the world alongside other objects, "an organism of the sort that physiology expounds" (p. 59). We can causally interact with other things in the world by virtue of this physical nature. But our embodiment is not exhausted by our physiology. This is because, on the other hand, we are also lived bodies: we experience an immediate first-person intimacy with our bodies from the inside. And from this first-person perspective, the body is experientially manifest not as an object or content of our perception, belief, or attitude, but rather as the transparent vehicle through which we engage with the world and others (p. 65). Simply put, to be an embodied subject for Watsuji is to concretely realize the space between pure objectivity and pure subjectivity.

Insofar as aidagara is rooted in the basic structures of our embodiment and agency, Watsuji argues that it is amenable to phenomenological analysis. Rinrigaku is his attempt to offer such an analysis. But this does not mean that Watsuji uncritically adopts the methods and concepts of his phenomenological peers. To make this point clearer, we can further unpack this embodied reading of aidagara by linking it with Watsuji's discussion of intentionality - a phenomenological characterization that builds on the work 
of Husserl, Heidegger, and Merleau-Ponty but that also departs from their analysis in some important ways, too.

\section{Intentionality and Betweenness}

In its technical phenomenological usage, "intentionality" - from the Latin verb intendo ("aim," "hold out," or "stretch")—refers to the way that consciousness can be about things, that is, the way it can stretch out or be directed toward objects both internal (mental images, memories, fictional objects) and external (things, relations, and events in the world). Conscious mental states are never empty; they always take objects that provide their content. Since intentionality is a central feature of consciousness-it captures the capacity of consciousness to transcend itself and reach out and grasp a meaningful world - the task of phenomenology is therefore a careful investigation of the character and structure of our various intentional relations with the world and things in it (Krueger 2019a).

For Husserl, intentionality belongs first and foremost to consciousness. This is because experiences are what direct us to various objects and present those objects as meaningful. In other words, these experiences "constitute," to use a technical phenomenological term, the manner or "how" of an object's appearance to consciousness: as an object of perception, judgment, belief, memory, desire, and so forth. To be clear, this does not mean for Husserl that consciousness somehow creates the object that it constitutes; nor does it mean that phenomenologists think we only ever experience internal representations of a mind-independent world. Despite other oftensignificant differences, early phenomenologists all insist that mind and world are fundamentally bound up with one another; the intentional openness of consciousness is part of its essential nature as embedded in the world, in direct contact with the people and things around it (Zahavi 2008). The point of this "constitution talk" is to highlight the fact that we always experience objects in particular sorts of ways, via distinctive meanings that determine their salience and character.

For example, I can see an apple as a piece of fruit, as something that invites eating, or as something that belongs to a colleague such as when I'm hungrily scanning the contents of a shared refrigerator at work; I can also judge that the apple is overripe, desire that it was less so, believe that it's a Gala apple, assess that it affords throwing, and so forth. In these cases, I experience the same apple. But I do so via different modes of presentation, different experiential structures that allow the apple to manifest in my experience of it in different ways. According to phenomenologists, this "how" of an object's appearance to consciousness, its mode of presentation, reflects the constituting activity of the subject. Subjects play an active role in shaping the form and meaning of their experience. Once more, however, since intentionality is a relational phenomenon for phenomenologists (i.e., 
not something confined to the head), this activity is part of experiential structures that lead us back to the world-to the objects these modes of appearance are correlated with. As Husserl tells us:

[T] he objects of which we are "conscious," are not found simply in consciousness as in a box, so that they can merely be found in it and snatched at in it; . . they are first constituted as being what they are for us, and as what they count as for us, in varying forms of objective intention. (Husserl 2001, p. 276)

Despite Husserl's repeated insistence on the world-engaged character of intentionality, subsequent phenomenologists like Heidegger and MerleauPonty-and Watsuji, as we will see-nevertheless challenge what they perceive to be the unwelcome Cartesian and idealist elements of Husserl's account of intentionality, at least in its early formulations. ${ }^{3}$ Heidegger, for example, argues that intentionality is a feature of Dasein's entire way of being-in-the-world. Accordingly, he develops his analysis of intentionalityor, as he prefers, "comportment" (Verhaltung)—by focusing on not mental activity alone but rather the various ways that a meaningful world is disclosed via our historically conditioned projects. Similarly, Merleau-Ponty reacts to what he sees as Husserl's excessive cognitivism by foregrounding the bodily dimension of intentionality: a "motor intentionality," or form of bodily understanding, that allows us to remain spontaneously open and responsive to the people and things around us.

At first blush, Watsuji's critique appears simply to echo themes found in Heidegger and Merleau-Ponty. He expresses similar concerns about the excessively cognitivist overtones he finds in Husserlian approaches to intentionality. Instead of characterizing intentionality as an intrinsic feature of individual mental states, Watsuji prefers to speak of "practical actconnections": ongoing patterns of worldly engagements in which individuals enter into "relationships of reciprocal activity" with their environment (Watsuji 1996, p. 33). In the activity of seeing, for example, we don't passively register our environment; we engage with it: seeing is a kind of doing. As Watsuji puts it, "[c]oncretely speaking, we perform the activity of seeing, not merely that of intentional activity" (p. 34). Within our activities of seeing we touch, handle, probe, manipulate, and actively negotiate the things and spaces around us. And these things and spaces, in turn, engage with us; they help specify the character and content of visual perception by resisting, yielding, breaking, changing, or otherwise responding to the patterns and dynamics of our ongoing engagements. ${ }^{4}$ Similarly, in the "betweenness" of seeing another person, "one's activity of seeing, is a seeing determined, conversely, by its being seen by the other" (p. 33). For Watsuji, social perception is also a reciprocally determined activity: "seeing each other, staring, looking angrily at, glimpsing, looking at nervously, seeing while pretending not to see, gazing on in rapture, and so forth" are jointly constructed processes involving complex tangles of feedback distributed 
across multiple subjects (p. 33). In sum, intentionality for Watsuji is a robustly embodied and situated affair-an ongoing activity of disclosing a meaningful world within various forms of reciprocity and betweenness.

\section{The Social Character of Intentionality}

Already this brief summary is enough to mark Watsuji as having made a useful contribution to phenomenological approaches to intentionality. However, Watsuji develops a stronger-and potentially more radicalcritique of individualist approaches to intentionality than either Heidegger or Merleau-Ponty. As we will see later, this stronger critique is where Watsuji's analysis becomes particularly useful in illuminating the character of some experiential disturbances in schizophrenia.

Simply put, Watsuji argues that consciousness and intentionality are constitutively social. From the start, consciousness is regulated by various sociocultural forms of betweenness that specify its intentional character and content. So, his worry is not (following Heidegger and Merleau-Ponty) just that orthodox approaches overlook the practical and bodily character of intentionality, although he thinks they do. Rather, the idea is that all forms of intentionality depend upon-insofar as they are regulated and sustained by-our interactions with others, that is, by the dynamics of betweenness. As he puts it: "No matter which aspect of consciousness we may lay hold of, none can be said to be essentially independent. The independent consciousness of $I$ is acquired only when isolated from any connection at all with other consciousnesses" (Watsuji 1996, p. 80). Similarly, elsewhere he tells us that "What is called intentional activity is nothing more than the product of abstraction that first of all excludes the relational elements from our acts, and then posits the residue as an activity of individual consciousness" (p. 34).

To be clear-and despite Watsuji's sometimes overstated protestations to the contrary ${ }^{5}$ - early phenomenologists are also sensitive to the connection between intentionality and sociality. Husserl, for example, argues for the central role of intersubjectivity in constituting our experience of the world. He insists that our ability to experience objects as transcendent-that is, as objective mind-independent phenomena-depends upon our awareness that these objects can be experienced by other subjects. In other words, an object's intersubjective accessibility - the fact that it is potentially given to another subject as an object of their experience-guarantees its real transcendence (Zahavi 2003, pp. 115-116). Heidegger, for his part, argues that the rich network of artifacts, practices, and projects into which Dasein is "thrown" comprise historically conditioned contexts whose meanings and possibilities are largely established by others. Watsuji would agree with these claims. However, he appears to be making an even stronger claim, namely that the "deep structure" of intentionality, as we might refer to it, is 
constitutively regulated by features of the betweenness within which that intentional activity first arises.

One argumentative strategy Watsuji uses to defend this claim is to select candidate experiences that initially appear to be examples of experiences "essentially independent" of the social world (i.e., betweenness), and then show that these experiences nevertheless remain irreducibly social insofar as their intentional structure is regulated by "specific social forms" that preexist our individual development (Watsuji 1996, p. 74). To head off an immediate worry: Watsuji is not suggesting that individual subjects cannot realize their own unique set of token experiences. He would not dispute, for example, that the slight twinge in my lower back or growing fatigue I feel from sitting in front of my computer too long are my experiences, manifest at this moment only to me. His point, rather, is that these token experiences-like all episodes of consciousness-are inextricably regulated by their interpersonal milieu, hence their social nature. Looking at some of his examples will help clarify the scope of his claim.

Consider first desires (Watsuji 1996, p. 73). We might think that we are individuated as conscious subjects by our constellation of idiosyncratic desires, for example aesthetic preferences, sexual desires, and so forth. But Watsuji disagrees. While token episodes of desiring (e.g., a piece of cake, a Belgian beer, a holiday, lusting after a celebrity) may be uniquely ours, both the character and content of our desire-the way it is manifest from within the desiring experience, its particular mode of presentation-are only intelligible against a shared intersubjective milieu or "communal consciousness," as he puts it, in which the desire "is socially qualified or modified" (p. 74). More simply, we learn from others both what to desire and how to desire it, including how to enact bodily practices for satiating and sustaining these desires.

As I read Watsuji, this is not just the claim that desires are "contagious" insofar as we often inherit them from the people around us via cultural narratives, media, and advertising, or the enthusiasm of family members and friends-although Watsuji would probably agree. His more interesting claim, I think, is that the social modulation of our desiring practices runs even deeper than this sort of external desire contagion. In short, we learn how to constitute intentional objects as desirable from others. This is because, via deeply enculturated "somatic modes of attention" (Csordas 1993), we first become bodily sensitive to features of our world that manifest as worthy of our desirous attention; these modes of attention and expression are regulated from birth by the ongoing input of those around us, particularly caregivers who shape the early development of attentional practices that bring specific parts of the world into view (while occluding others) and present them as worthy of desiring in the first place (Krueger 2013b; Spurrett and Cowley 2010) (more on this point below). The important point, then, is that the ontogenesis of these somatic modes of attention-by which the world is 
constituted as a rich landscape of potential desire-worthy objects-does not unfold independently of others, based solely on our own endogenous capacities. Rather, these forms of attention are elaborated within phenomenological structures and bodily practices that constitutively depend upon the ongoing support and regulation of our sociocultural betweenness. If this point still seems somewhat elusive, the second example Watsuji considers may help clarify further (I will also consider some relevant empirical literature).

A second candidate for an experience we might think is "essentially independent" of the social world is visual perception (Watsuji 1996, p. 73). Since perception connects most directly with phenomenological discussions of intentionality - and it might initially appear to be the most promising candidate for a genuinely individualistic experience-it is worth looking at in more detail. Watsuji begins by asking us to imagine a simple experience: staring at a wall. This experience initially appears, he suggests, to be an authentically individualistic experience insofar as it is an experience "of the "I" as existing alone, in which there is no one else with whom the "I" shares the same consciousness" (p. 73). Put another way, it seems that how the wall appears, experientially-its mode of presentation as an object of my visual perception-is specified independently of my connection with others. I simply see it, or I don't. And my visual system would work the way that it does even if I had never encountered another person.

In one sense, of course, this experience is an individual experience. At that moment, the token "staring at the wall" experience realized by my perceptual consciousness is uniquely mine. Even if someone else is standing very close to me and staring at the same point of the wall, they will have their own token experience, numerically distinct from mine. However, once again, Watsuji's claim does not entail the implausible rejection of the numerical distinctiveness of token episodes of experience. Rather, the idea seems to be that every token episode reflects a sociocultural type. In other words, even in these kinds of highly sanitized, stripped-down experiences, sociocultural betweenness regulates the intentional character and content of such experiences. In this sense do we "share the same consciousness," as Watsuji puts it.

Watsuji's argument here is phenomenological. He tells us that, in seeing a wall as a wall, "social consciousness has already intervened" (Watsuji 1996, p. 73). This is because walls have specific forms and functionsmeanings - that both reflect their sociocultural context and distinguish them from other intentional objects such as desks, books, trees, and other people. In other words, we do not first perceive uninterpreted sensory units (colors, shapes, textures, etc.), and only then integrate and assign them meaning. Rather, intentional objects like walls show up, experientially, as already saturated with meaning, as embedded in shared contexts that specify their salience and significance. As Watsuji tells us: 
The consciousness we possess in our daily lives is never a collection of sensations. Even when we remain in our study alone, we are still conscious of a wall as a wall, of a desk as a desk, and of a book as a book.... [F]rom the beginning we must concern ourselves with tools and assume there is no more primitive consciousness than this concern. (p. 73)

The important point here for Watsuji is that the form these tools take-the "how" by which they manifest as meaning-saturated intentional objects-is not the product of an individual consciousness but "rather exhibits a meaning common to all those who are concerned with this tool" (p. 73). Things like walls, tables, and desks have structures, names, and functions that reflect the sociocultural betweenness in which they are situated. This betweenness regulates how things and spaces show up for consciousness as meaningful (intentional) objects of experience.

Before concluding this section, we can note that there are different streams of empirical evidence that appear to support Watsuji's claim about the interrelation of betweenness, attention, and visual perception. These studies suggest that basic attentional processes by which individuals constitute intentional objects may be modulated by the sociocultural contexts in which these processes arise. For example, Chua and colleagues (2005) conducted eye-tracking studies with East Asian and American subjects. They found that when presented with images of animals and of non-living objects like cars, planes, and boats, East Asian subjects spent more time looking at the background of objects than did their American counterparts. They conclude that this variation in eye movements indicates a difference in terms of how attentional resources are allocated-a variation that stems, in part, from different factors in experience, expertise, and, crucially, socialization. ${ }^{6}$ One important socialization factor the authors single out is child rearing practices (see also Chan et al. 2009; Fernald and Morikawa 1993). They observe:

East Asians live in relatively complex social networks with prescribed role relations. Attention to context is, therefore, important for effective functioning. In contrast, Westerners live in less constraining social worlds that stress independence and allow them to pay less attention to context. (p. 12633)

Accordingly, because attention management is, from birth, a socially scaffolded process (Krueger 2013b), different cultural expectations about roles, relations, and norm-governed practices will shape how caregivers teach infants to selectively attend to the world around them. Infants learn to constitute their world of experience in ways that reflect their situatedness in richly structured contexts of betweenness.

Other evidence supports this claim. For instance, similar cultural variations in attention have been found in studies of Canadian and Japanese children's drawings (Senzaki et al. 2014). The former tends to adopt objectfocused drawing styles whereas the latter place the horizon higher in visual 
space in order to include more contextual information. Even 24-month-old infants (e.g., American and Chinese) already exhibit similar culturally inflected patterns of attention (Waxman et al. 2016). The takeaway point, then, is that this evidence-in line with Watsuji's betweenness-based arguments-suggests that fundamental mechanisms by which the world shows up as a potential object of experience are not impervious to the influence of betweenness. Intentionality is social all the way down.

\section{The Anticipatory Structure of Intentionality}

Watsuji's analysis of the social character of intentionality harbors a second important dimension worth considering. We can make this second dimension clearer by returning to his discussion of "reciprocity." As we've seen, for Watsuji intentionality is an active, world-engaged process. We not only engage with the world; the world, in turn, engages with us. When I reach out and pick up my coffee mug, that mug provides ongoing feedback specifying possible things I can do with it. Because it has a distinctive size, solidity, texture, and structure-and because, moreover, I have a body with a particular set of sensorimotor skills and habits-I can grasp and use it in a way I can't, say, with an egg, dandelion, or ladybug. There is a sense in which the character of the mug, as an intentional object, tells me what I can do with it; how it shows up in my experience is as an object that both affords and occludes certain interactive possibilities.

Put differently, for Watsuji this back-and-forth reciprocity specifies a field of possibilities, or set of anticipations, that are part of the character of our experience. This idea is found in somewhat elusive formulations such as when, approvingly citing Heidegger, Watsuji writes:

"A being there," despite existing in the world, finds space in its concern with what is at hand. Tools are "at hand," or in their region (Gegend) and occupy their place (Platz). Space such as an environmental region implies that it is itself in the world but is not a field that renders possible the world within itself. For this region, the ontological subject is itself spatial, as a being in the world. (Watsuji 1996, p. 174)

For Watsuji, "ontological subjects" live the spaces they inhabit-they aren't simply passively situated in these spaces but can actively transcend themand therefore they perceive further interactive possibilities via the "practical interconnections" that exist between themselves and the meaningful things they engage with. Simply making coffee in the morning, turning on my computer to begin writing, or emptying the trash is an active reconfiguration of my lived space and the possibilities that comprise that space.

However, as is always the case for Watsuji, this anticipatory character of experience harbors an irreducible social dimension operative at a fundamental level. This is because individuals perceive a landscape of possibilities 
only insofar as they are rooted in a shared world with others. As Watsuji tells us, this time critiquing what he sees as Heidegger's neglect of the social:

A subjectivity based on a concern with tools is possible only if tools are already established in human relationships. Only when we extract the element of the individual from these human relationships and keep our focus on the individual while considering his human activities are we able to come to grips with the concern with tools. (Watsuji 1996, p. 175)

What this seems to mean for Watsuji is that tools like hammers, smartphones, and hymnals only acquire their meaning-and afford their respective interactive possibilities_insofar as they are persistently situated within intersubjective space, that is, rich networks of customs and practices in which "these tools have already emerged out of those human relationships involved in collective labor" (p. 176). So, the point for Watsuji is not just that we learn how to use things by watching others (although we do). Rather, the more subtle point is that the salience of a tool's interactive possibilities, the range of things we can potentially do with it, is in some "deep" sense modulated, in an ongoing way, by our persistent connection with others and a shared world. To return to analysis from the previous section: how a tool is constituted as an intentional object-including what sort of interactive possibilities it affords-depends upon the features of the tool as well as on our ongoing connection with others. For Watsuji, the anticipatory character of intentionality is thus coextensive with a persistent sense of betweenness. As we will see shortly, this idea gains plausibility when we see that, in schizophrenia, a disturbance of the latter potentially ramifies throughout the former.

Before turning to psychopathology, however, we can further unpack Watsuji's claim here by noting that within the phenomenological tradition, both Husserl and Merleau-Ponty use the concept of "horizon" to capture this anticipatory structure of intentionality. Simply put, the "horizonal" structure of experience refers to the fact that, when perceiving something like a mug, we experience the mug as wholly present, even though, strictly speaking, we only see the part facing us at that moment. Additionally, we experience the mug as stable and unchanging even as our relationship to it changes - that is, we move nearer, farther away, walk around it, grasp it, rotate it in our grip, and so forth-and accordingly perceive the whole object via momentary and partial appearances. How is this possible?

For phenomenologists, it is because we perceive what is both present and possible; the latter is as constitutive of perception as is the former. In other words, we experience what is perceivable from our current vantage point as well as other possible vantage points that we or others can potentially adopt: "Everywhere, apprehension includes in itself, by the mediation of a 'sense', empty horizons of 'possible perceptions'; thus I can, 
at any given time, enter into a system of possible and, if I follow them up, actual, perceptual nexuses" (Husserl 1989, p. 42). Elsewhere, Husserlanticipating Merleau-Ponty's emphasis on the motor dimension of intentionality-clarifies that horizons involve a kinaesthetic element or mode of active anticipation:

The possibilities of transition are practical possibilities, at least when it is a question of an object which is given as enduring without change. There is thus a freedom to run through the appearances in such a way that I move my eyes, my head, alter the posture of my body, go around the object, direct my regard toward it, and so on. We call these movements, which belong to the essence of perception and serve to bring the object of perception to givenness from all sides insofar as possible, kinaestheses. (Husserl 1973, pp. 83-84)

To be clear, the anticipatory "horizon" is not an addition to, or extra element within, our experience. Rather, it is constitutive of our experience of what an object is-and, crucially for our purposes, how it is manifest to consciousness, its mode of presentation as an intentional object.

Again, what is particularly important here for this discussion is that, for Watsuji, this anticipatory horizon is often regulated not just by our sensorimotor capacities but also by our sociocultural milieu: the intersubjective space in which intentional objects stand out with their distinctive salience and significance. To help motivate this idea, consider an example provided by van den Berg: the different ways that the same city can appear, experientially, when showing a guest around town. He writes:

$[\mathrm{O}]$ ne can learn to know another best by traveling with him through a country or by looking at a town with him. One who often shows the same town to different people will be struck by the ever new way in which this town appears in the conversation that is held about the sights during such a walk. These different ways are identical with the people with whom one walks, they are forms of subjectivity. (van den Berg 1952, p. 166)

In van den Berg's example, as we stroll around the city pointing out sites of interest, the ongoing input of our guest will regulate the character of how we experience the city, how it shows up as an intentional object. If our guest is dismissive or uninterested, the city will appear flat and lifeless, devoid of compelling features or possibilities that previously excited us. Jointly experiencing something with another can thus impoverish or downregulate our experience of it. As van den Berg observes, "We all know people in whose company we would prefer not to go shopping, not to visit a museum, not to look at a landscape, because we would like to keep these things unharmed" (van den Berg 1972, p. 65). Of course, the presence of others can deeply enrich our experience, too, such as when they enthusiastically respond to our tour and affirm our appreciation of the city's compelling qualities. Their input may even open us up to new interactive 
possibilities that we had not previously experienced-or perhaps enable us to see familiar possibilities in a new and fresh way.

To conclude this section, the salient point is that the feeling of being with others shapes and regulates, in an ongoing way, the anticipatory character of how we experience the world in their presence-including what interactive possibilities are manifest as present (or absent, as the case may be). And the more general takeaway message is that, for Watsuji, the character of how some intentional objects appear to us-their particular "how" or mode of presentation-does not simply reflect features of our neurophysiology, our sensorimotor capacities, or even features of the objects and spaces themselves. Additionally, this character is shaped and regulated by the social world, including the feeling of what we can do with others. In this way is the deep structure of intentionality bound up with betweenness. As we will now see, when this persistent feeling of being rooted in a shared world with others is lost-such as we find in psychopathological conditions like schizophreniathe integrity and stability of experience can become deeply compromised.

\section{Psychopathology and Disturbances of Intentionality and Betweenness}

I now argue that Watsuji's characterization of the social character of intentionality is useful for illuminating subtle experiential anomalies distinctive of schizophrenia, particularly in the prodromal phase preceding the onset of full-blown psychosis. More precisely, it can help illuminate subtle disturbances of intentionality, including how these disturbances flow from a loss of persistent connectedness with the social world. I begin with a brief background.

\section{Kimura, Schizophrenia, and the Ipseity-Disturbance Model of Schizophrenia}

I am not the first to see a link between Watsuji's work on betweenness and psychopathology. The Japanese psychiatrist Bin Kimura explicitly appeals to Watsuji in various texts exploring the character of different mental disorders (Stevens 2003; Van Duppen 2017). For example, Kimura argues that a cluster of phobias common among Japanese patients but rarely found among non-Japanese patients - phobias that are, he says, part of a more "general fear of facing others" (taijin kyofu-sho), such as a fear that one's face is ugly or red, that one's body smells badly, or a fear of being looked at or making inappropriate eye contact—can be illuminated by acknowledging the predominantly relational or betweenness-oriented sense of self distinctive of Japanese culture (Kimura 1972; see also Arisaka 2001). Part of the anxious character of these disorders, Kimura argues, stems from the fear one experiences when anticipating the embarrassment these conditions may cause others (i.e., those who must view one's ugly face, smell one's offensive odor, etc.). 
Kimura also applies this betweenness-based framework to schizophrenia (Krueger 2019b). For Kimura, schizophrenia is more than just a brain disorder. It is a self-disorder-a multi-level disturbance of the individual's relationship with their world. At the heart of this disturbance, according to Kimura, is a disturbance of the sense of "I-ness," the preflective sense that one is an enduring subject of experience. However, Kimura-drawing upon Watsuji-argues that this disturbance also has an other-directed intersubjective dimension: a disruption of the "interpersonal between" weaving individuals into their sociocultural milieu, as he puts it. Kimura insists that these two dimensions "represent different aspects of one and the same basic occurrence of schizophrenic estrangement" (Kimura 1982, p. 182). Consequently, schizophrenia cannot be understood just by looking at functional disorders in the brain, or even by looking at disturbances of individual selfconsciousness. This is because it ultimately manifests as "a striking event of the interhuman world or as a pathology of the "between" in the most unmediated and unequivocal way" (pp. 178-179).

Others working in phenomenological psychopathology echo Kimura's characterization of schizophrenia as a self-disturbance. They argue that the generative disorder of schizophrenia is a disturbance of the first-person perspective: a disturbance of the "sense of mineness" that accompanies all episodes of consciousness (Sass and Parnas 2003; see also Henriksen and Nordgaard 2014, and Raballo et al. 2011). This sense of mineness is a minimal form of selfhood, the integrity of which is presupposed by other richer and more complex forms of selfhood (e.g., narrative forms of self). It refers to the first-person quality of experience- "the distinct manner, or how, of experiencing" that specifies intentional objects as given to me, in my field of experience (Zahavi 2014, p. 22). When I see a sunset, hear a bird's song, savor a rich whisky, or remember my deceased grandmother, I have these experiences in a first-personal way. I immediately recognize them as my own, as experiences that belong to me and not to someone else.

Some argue that this minimal self is altered or disturbed in schizophrenia. According to this so-called ipseity disturbance model (IDM)-ipse is Latin for "self" or "itself"-this disturbance can include a diminished sense of existing as a bodily subject, a weakened sense of ownership of one's thoughts and experience, a gradual fragmentation or loss of coherence of the field of awareness, and disturbed self-world, self-other boundaries (Parnas et al. 2005). Indications of this ipseity disturbance are found in reports from first-admitted patients. Individuals often describe feeling as though they do not exist, and that they lack an inner core or sense of immediacy with respect to their own experience. They say things like: "I have a feeling like it is not me experiencing the world; it feels as if another person was here instead of me"; "My feeling of experience as my own experience only appears a split second delayed"; and "My first-person perspective is replaced by a third-person perspective" (pp. 245-246). 
Phenomenological approaches to ipseity disturbances have proven useful for understanding early anomalous experiences in schizophrenia. In a clinical context, these descriptions can aid intervention efforts, assist differential diagnosis (since certain forms of self-disturbances appear unique to schizophrenia), and also increase our understanding of, and empathy for, the patient's lived experience-an empathy that in the context of a clinical interview can bring the patient some relief when they feel the interviewer is familiar with aspects of their experience (Henriksen and Nordgaard 2016, p. 278). However, ipseity approaches can be enriched by highlighting how various forms of disrupted intentionality co-occur with, or exacerbate, disruptions of ipseity. ${ }^{7}$ This is where Watsuji can help.

\section{Schizophrenia and Disturbances of Intentionality and Betweenness}

There is evidence that structures of intentionality can become altered or disturbed in schizophrenia. For example, Fuchs (2007) draws on Husserl's (1991) analysis of "inner time consciousness" to relate schizophrenic disorders to the temporal structure of consciousness and intentionality. According to Husserl, the temporal microstructure of consciousness-as intentional-consists of a dynamic self-organizing process comprised of both a retention of what was just perceived or thought and an anticipatory protention of what one expects to continue perceiving or thinking. A melody, for example, is only perceived as a melody insofar as we are aware not just of what is currently being played, but also of how the present notes relate to what has just been played, along with our anticipations of how the melody will continue. The coherence of experience thus exhibits a temporal "thickness." For Husserl, this temporal synthesis is a tacit background process organizing our experiences-and the intentional acts that comprise them-into sequences of coherent units. It is also crucial for organizing the anticipatory character of experience, discussed previously.

This temporal microstructure of intentional consciousness can become disturbed in schizophrenia (Fuchs 2007, p. 233). As a result, patients' capacity to make sense of situations and experiences-as well as others' behavior-is impaired. For example, in the early stages of psychosis, experiences such as the loss of one's train of thought, difficulty following conversations, or difficulty maintaining narrative coherence are common (see also Gallagher 2007). One patient says, "I'm a good listener but often I'm not really taking it in. I nod my head and smile but it's just a lot of jumbled up words to me" (McGhie and Chapman 1961, p. 106). Another says, "Time is somehow changed. It isn't supposed to be the way it is. I don't know in what way" (Sass et al. 2017, p. 24).

This temporal disruption also destabilizes the dynamics of motor intentional processes_our ability to enact "practical act-connections," as Watsuji terms them. One patient describes the experience this way: "I found 
recently that I was thinking of myself doing things before I would do them. If I am going to sit down, for example, I have got to think of myself and almost see myself sitting down before I do it. It's the same with other things like washing, eating, and even dressing" (McGhie and Chapman 1961, p. 107). In these cases, actions that are normally performed with an unreflective spontaneity are taken up in a deliberate and thoughtful way; each movement is considered in isolation from the others, leading to a "disautomation" that compromises the individual's ability to negotiate their physical and social environments smoothly (Fuchs 2007, p. 233).

Watsuji's analysis of the interrelation of intentionality and betweenness can help bring another important dimension of these disturbances to light. The idea, in short, is that disturbances of intentionality do not originate exclusively from more fundamental ipseity disturbances - that is, disturbances of a presocial minimal self-as is sometimes thought to be the case (e.g., see Raballo et al. 2011). Watsuji's analysis can instead help illuminate how erosions of betweenness potentially disrupt an individual's intentional relation with the world. As we saw previously, for Watsuji the character and structure of intentionality is constitutively dependent upon an individual's deep integration with their sociocultural environment. It follows, accordingly, that when certain aspects of this social integration are disrupted or lost altogether, the structural integrity and phenomenological stability of their experiences can become deeply compromised. This Watsuji-informed perspective therefore suggests that some of the causes of schizophrenia reside not solely within the individual but also within the dynamics of their broader relation to a shared world. Self-disturbances in schizophrenia are equally relational disturbances (Ratcliffe 2017a; see also Fuchs 2015 and Krueger 2018).

A full defense of this claim will have to wait for another time. Here, I will only offer a brief sketch. ${ }^{8}$ Consider first reports indicating how individuals with schizophrenia lose the persistent feeling that they are bodily rooted in a common intersubjective space with others. Many will say things like "People move weirdly about[,] ... make gestures, movements without sense"; "I simply cannot grasp what others do"; "There is a pane of glass between me and mankind"; "The others know the [social] rules; I have to study them" (Sass et al. 2017, pp. 26-27). Individuals describe how they feel as though they are cut off from the sociocultural and material aspects of betweenness that most of us take for granted in everyday life.

This felt lack of social rootedness flows, at least in part, from a disturbance of what Froese and Fuchs (2012) term "inter-bodily resonance" - the capacity to "resonate" with the bodily expressions and emotions of other people. It is well established that motor mimicry (i.e., spontaneous mimicry of others' facial expressions, gestures, movements, and intonation patterns) and behavioral synchrony (i.e., synchronizing speech 
rhythms and bodily movements over short and long-term timescales) are crucial mechanisms for social understanding (Bernieri and Rosenthal 1991; Wiltermuth and Heath 2009). When we interact with others, their expressive actions - their gestures, facial expressions, postural adjustments, intonation patterns, movements, manipulations of shared space, and so forth-have a direct impact on our bodily and emotional responses (Krueger 2011). These resonance processes promote social cohesion and strengthen feelings of connectedness, rapport, and cooperation (Lakin and Chartrand 2003; van Baaren et al. 2004). We might think of these processes as mechanisms responsible for the forms of bodily betweenness Watsuji describes.

These bodily processes are disturbed in schizophrenia. Not only do individuals describe how they feel a kind of experiential distance or alienation from their own body-for example "it's like I'm not in my body or not attached to it"; "My body feels alien to me" (Krueger and Henriksen 2016). This experiential disturbance is also manifest in the ways that individuals with schizophrenia exhibit diminished facial, gestural, and vocal expressivity, which in turn diminishes the sort of resonance responses they elicit from others (Kring and Elis 2013). Moreover, individuals with schizophrenia often show a deficit in their ability to detect and respond to the facial and gestural expressions of others (Amminger et al. 2012; Chan et al. 2010; Edwards et al. 2002). As a result, this lack of perceptual access and responsiveness to others' bodily expressions contributes to the individual's loss of social attunement and a general feeling of disconnectedness from others-a feeling, in other words, that they are not responsive participants within the dimensions and intensities of betweenness that characterize everyday life. This feeling is articulated in remarks like "There is a pane of glass between me and mankind"; "A wall of void isolates me from everybody" (Sass et al. 2017, p. 27).

For this discussion, the key point is that this disturbance of betweenness ramifies throughout schizophrenic individuals' intentional relations with the world and others. Changes in interpersonal experience at a basic bodily level affect the deep structure of intentionality-including its anticipatory dimension. This dimension, the integrity and character of which depends (as we saw above) on feeling a persistent connectedness with others, becomes unstable, ambiguous, and indeterminate: for example, "more and more, I lost the feeling of practical things"; "objects are stage trappings placed here and there, geometric cubes without meaning"; "the others know the rules; I have to study them" (Sass et al. 2017, pp. 37, 38, 27). By virtue of their disturbed bodily betweenness, individuals become viscerally isolated from a public world writ large; become disengaged from the everyday projects, possibilities, and practical activities that continually affirm our connections with others; fail to receive forms of interpersonal 
validation both small and large; and, as we've seen, fall out-of-sync with the shared emotions, concerns, and wider structures that govern our myriad encounters with others and our joint actions in the world (Ratcliffe 2017b, 151).

As a result, the character of how the world appears, experientially-its manifestation as an intentional object-is altered without the persistent scaffolding of this betweenness. Ratcliffe puts this point well when he tells us that "The kinds of possibility attached to entities in the surrounding environment are, to a substantial degree, consistent and enduring, a consistency that depends partly on relations with others" (Ratcliffe 2017a, p. 159). When these relations become disturbed, the character of intentional processes that disclose possibilities "attached to entities" are also compromised. Self-disturbances in schizophrenia are thus equally relational disturbances-disturbances of betweenness.

\section{Conclusion}

I have argued that Watsuji develops a philosophically rich and timely characterization of intentionality worthy of further attention. His account productively stresses the centrality of embodiment and agency. For Watsuji, intentionality is not an intrinsic feature of mental states but rather a relational property of the whole person engaging with the things, spaces, and people in a common world. More strongly, for Watsuji features of this shared world are, as we have seen, constituent features of the intentional processes that bind us to this very world. The character and content of our intentional acts-which determine how the world and things in it show up as objects of experience-are deeply regulated by betweenness. Accordingly, we cannot understand intentionality without considering its constitutive interrelation with betweenness.

However, Watsuji's view here is of interest not simply to phenomenologists. I have argued further that this social characterization of intentionality can help further illuminate experiential anomalies in psychopathology, and particularly schizophrenia. Building upon Kimura's Watsuji-inspired approach, I have argued that thinking of schizophrenia exclusively as a selfdisorder may be too narrow a perspective. What is needed, rather, is a framework that brings to light the irreducibly relational character of such self-disturbances - that is, a framework that helps to understand how losing touch with others is, simultaneously, to lose touch with the resources that give us a world of experience in the first place. A better understanding of such experiences can deepen our empathy for those in their grip and equip us with conceptual and clinical resources to reach them more effectively. As in many other areas, Watsuji can contribute important theoretical tools for undertaking this work. 
Notes

1 - For a helpful overview and bibliography, see Carter and McCarthy 2017.

2 - See Mayeda 2006 for a detailed look at Watsuji's critical relationship with Heidegger.

3 - Whether or not Husserl is guilty of these sins (probably not) need not concern us here. For absolution, see Zahavi 2017, pp. 77-136, and Moran 2017. Nevertheless, there are contemporary theorists who are happy to locate intentionality entirely in the head and limit it to traditionally defined internal mental states. Horgan and Kriegel (2008), for example, defend a "strongly internalist, broadly Cartesian picture of the mind" and phenomenal intentionality. For an alternative enactive view-closer in spirit to Watsuji (although they don't discuss him)—see Gallagher and Miyahara 2012.

4 - Some of Watsuji's formulations here and elsewhere anticipate recent enactive approaches to cognition that stress the central role played by agency in structuring cognitive, perceptual, and affective processes (e.g., Colombetti 2014; Gallagher 2017; Noë 2009).

5 - For example, he says that "phenomenology from beginning to end analyzed individual consciousness only. Even after attention was deepened from consciousness to being, it was still concerned with 'individual being'" (Watsuji 1996, p. 219).

6 - Similar effects have been observed in the visual perception of objects and space (Boduroglu et al. 2009; Kelly et al. 2010; Saulton et al. 2017).

7 - For a related friendly critique of the potential narrowness of ipseity approaches, see Krueger 2018.

8 - Ratcliffe (2017a, 2017b) defends a social account of self-disturbances in schizophrenia very close to the one I am advocating here.

\section{References}

Amminger, G. Paul, Miriam R. Schäfer, Konstantinos Papageorgiou, Claudia M. Klier, Monika Schlögelhofer, Nilufar Mossaheb, Sonja WerneckRohrer, Barnaby Nelson, and Patrick D. McGorry. 2012. "Emotion Recognition in Individuals at Clinical High-Risk for Schizophrenia." Schizophrenia Bulletin 38, no. 5:1030-1039.

Arisaka, Y. 2001. "The Ontological Co-Emergence of 'Self and Other' in Japanese Philosophy." Journal of Consciousness Studies 8, nos. 5-7:197-208. 
Bernieri, Frank J., and Robert Rosenthal. 1991. "Interpersonal Coordination: Behavior Matching and Interactional Synchrony." In Fundamentals of Nonverbal Behavior, edited by R. S. Feldman and B. Rime, pp. 401-432. Cambridge: Cambridge University Press.

Boduroglu, Aysecan, Priti Shah, and Richard E. Nisbett. 2009. "Cultural Differences in Allocation of Attention in Visual Information Processing." Journal of Cross-Cultural Psychology 40, no. 3:349-360.

Carter, Robert, and Erin McCarthy. 2017. "Watsuji Tetsurô." In The Stanford Encyclopedia of Philosophy, edited by Edward N. Zalta (Metaphysics Research Lab, Stanford University, Spring 2017). https://plato.stanford. edu/archives/spr2017/entries/watsuji-tetsuro/.

Chan, Cheri C. Y., Amanda C. Brandone, and Twila Tardif. 2009. "Culture, Context, or Behavioral Control? English- and Mandarin-Speaking Mothers' Use of Nouns and Verbs in Joint Book Reading." Journal of Cross-Cultural Psychology 40, no. 4:584-602.

Chan, Raymond C. K., Huijie Li, Eric F. C. Cheung, and Qi-Yong Gong. 2010. "Impaired Facial Emotion Perception in Schizophrenia: A MetaAnalysis." Psychiatry Research 178, no. 2:381-390.

Chua, Hannah Faye, Julie E. Boland, and Richard E. Nisbett. 2005. "Cultural Variation in Eye Movements during Scene Perception." Proceedings of the National Academy of Sciences of the United States of America 102, no. 35:12629-12633.

Colombetti, Giovanna. 2014. The Feeling Body: Affective Science Meets the Enactive Mind. Cambridge, MA: MIT Press.

Csordas, Thomas J. 1993. "Somatic Modes of Attention." Cultural Anthropology: Journal of the Society for Cultural Anthropology 8, no. 2:135-156.

Edwards, Jane, Henry J. Jackson, and Philippa E. Pattison. 2002. "Emotion Recognition via Facial Expression and Affective Prosody in Schizophrenia: A Methodological Review." Clinical Psychology Review 22, no. 6:789-832.

Fernald, A., and H. Morikawa. 1993. "Common Themes and Cultural Variations in Japanese and American Mothers' Speech to Infants." Child Development 64, no. 3:637-656.

Froese, Tom, and Thomas Fuchs. 2012. "The Extended Body: A Case Study in the Neurophenomenology of Social Interaction." Phenomenology and the Cognitive Sciences 11, no. 2:205-235.

Fuchs, Thomas. 2007. "The Temporal Structure of Intentionality and Its Disturbance in Schizophrenia." Psychopathology 40, no. 4:229-235.

. 2015. "Pathologies of Intersubjectivity in Autism and Schizophrenia." Journal of Consciousness Studies 22, nos. 1-2:191-214. 
Gallagher, Shaun. 2007. "Pathologies in Narrative Structures." Royal Institute of Philosophy Supplements 60:203-224.

- 2017. Enactivist Interventions: Rethinking the Mind. Oxford: Oxford University Press.

Gallagher, Shaun, and Katsunori Miyahara. 2012. "Neo-Pragmatism and Enactive Intentionality." In Action, Perception and the Brain: Adaptation and Cephalic Expression, edited by Jay Schulkin, pp. 117-146. London: Palgrave Macmillan UK.

Henriksen, Mads Gram, and Julie Nordgaard. 2014. "Schizophrenia as a Disorder of the Self." Journal of Psychopathology and Behavioral Assessment 20:435-441.

_ 2016. "Self-Disorders in Schizophrenia." In An Experiential Approach to Psychopathology —What is it Like to Suffer from Mental Disorder? edited by Giovanni Stanghellini and Massimiliano Aragona, pp. 265-280. Springer.

Horgan, Terry, and Uriah Kriegel. 2008. "Phenomenal Intentionality Meets the Extended Mind." The Monist 91, no. 2:347-373.

Husserl, Edmund. 1973. Experience and Judgment. Translated by James Spencer Churchill and Karl Ameriks. London: Routledge.

- 1989. Ideas Pertaining to a Pure Phenomenology and to a Phenomenological Philosophy: Second Book: Studies in the Phenomenology of Constitution. Translated by R. Rojcewicz and A. Schuwer. Dordrecht: Kluwer Academic Publishers.

- 1991. On the Phenomenology of the Consciousness of Internal Time. Translated by John Barnett Brough. 1991 edition. Dordrecht and Boston: Springer.

—. (1900-1901) 2001. Logical Investigations. Translated by J. N. Findlay. Vols. 1-2. London: Routledge.

Kelly, David J., Sébastien Miellet, and Roberto Caldara. 2010. "Culture Shapes Eye Movements for Visually Homogeneous Objects." Frontiers in Psychology 1, no. 6:1-7.

Kimura Bin 木村敏. 1972. Hito to hito to no aida: Seishin byōrigakuteki Nihonron 人と人との間: 精神病理学的日本論. Tokyo: Kobundo.

_ 1982. "The Phenomenology of the Between: On the Problem of the Basic Disturbance in Schizophrenia." In Phenomenology and Psychiatry, edited by A.J.J. De Koning and F. A. Jenner, pp. 173-186. New York: Academic Press.

Kring, Ann M., and Ori Elis. 2013. "Emotion Deficits in People with Schizophrenia." Annual Review of Clinical Psychology 9:409-433. 
Krueger, Joel. 2011. "Extended Cognition and the Space of Social Interaction." Consciousness and Cognition 20, no. 3:643-657.

—. 2013a. "Watsuji's Phenomenology of Embodiment and Social Space." Philosophy East and West 63, no. 2:127-152.

— 2013b. "Ontogenesis of the Socially Extended Mind." Cognitive Systems Research 25-26 (December): 40-46.

- 2018. "Schizophrenia and the Scaffolded Self." Topoi: An International Review of Philosophy. doi:10.1007/s11245-018-9547-3.

—. 2019a. "Intentionality." In The Oxford Handbook of Phenomenological Psychopathology, edited by Giovanni Stanghellini, Andrea Raballo, Matthew Broome, Anthony Vincent Fernandez, Paolo FusarPoli, and René Rosfort, pp. 325-334. Oxford: Oxford University Press.

- 2019b. "Watsuji's Phenomenology of Aidagara: An Interpretation and Application to Psychopathology." In Tetsugaku Companion to Phenomenology and Japanese Philosophy, edited by Shigeru Taguchi and Andrea Altobrando. Cham, Switzerland: Springer.

Krueger, Joel, and Mads Gram Henriksen. 2016. "Embodiment and Affectivity in Moebius Syndrome and Schizophrenia: A Phenomenological Analysis." In Phenomenology for the Twenty-First Century, edited by J. Aaron Simmons and James Hackett, pp. 249-267. London: Palgrave Macmillan UK.

Lakin, Jessica L., and Tanya L. Chartrand. 2003. "Using Nonconscious Behavioral Mimicry to Create Affiliation and Rapport." Psychological Science 14, no. 4:334-339.

Mayeda, Graham. 2006. Time, Space and Ethics in the Philosophy of Watsuji Tetsurō, Kuki Shūzō, and Martin Heidegger. New York: Routledge.

McCarthy, Erin. 2011a. "Beyond the Binary: Watsuji Testurō and Luce Irigaray on Body, Self, and Ethics." In Japanese and Continental Philosophy: Conversations with the Kyoto School, edited by Bret Wingfield Davis, Brian Schroeder, and Jason Wirth, pp. 212-228. Bloomington: Indiana University Press.

- 2011b. Ethics Embodied: Rethinking Selfhood Through Continental, Japanese, and Feminist Philosophies. Reprint. Lanham, MD: Lexington Books.

McGhie, Andrew, and James Chapman. 1961. "Disorders of Attention and Perception in Early Schizophrenia." The British Journal of Medical Psychology 34, no. 2:103-116.

Moran, Dermot. 2017. "Intercorporeality and Intersubjectivity: A Phenomenological Exploration of Embodiment." In Embodiment, Enaction, and Culture: Investigating the Constitution of the Shared World, edited by 
Christoph Durt, Thomas Fuchs, and Christian Tewes, pp. 25-46. Cambridge, MA: MIT Press.

Noë, Alva. 2009. Out of Our Heads: Why You Are Not Your Brain, and Other Lessons from the Biology of Consciousness. New York: Hill and Wang.

Parnas, Josef, Paul Møller, Tilo Kircher, Jørgen Thalbitzer, Lennart Jansson, Peter Handest, and Dan Zahavi. 2005. "EASE: Examination of Anomalous Self-Experience." Psychopathology 38, no. 5:236-258.

Raballo, Andrea, Ditte Saebye, and Josef Parnas. 2011. "Looking at the Schizophrenia Spectrum Through the Prism of Self-Disorders: An Empirical Study." Schizophrenia Bulletin 37, no. 2:344-351.

Ratcliffe, Matthew. 2017a. "Selfhood, Schizophrenia, and the Interpersonal Regulation of Experience." In Embodiment, Enaction, and Culture: Investigating the Constitution of the Shared World, edited by Christoph Durt, Thomas Fuchs, and Christian Tewes, pp. 149-171. Cambridge, MA: MIT Press.

- 2017b. Real Hallucinations: Psychiatric IIIness, Intentionality, and the Interpersonal World. Cambridge, MA: MIT Press.

Sass, Louis A., and Josef Parnas. 2003. "Schizophrenia, Consciousness, and the Self." Schizophrenia Bulletin 29, no. 3:427-444.

Sass, Louis, Elizabeth Pienkos, Borut Škodlar, Giovanni Stanghellini, Thomas Fuchs, Josef Parnas, and Nev Jones. 2017. "EAWE: Examination of Anomalous World Experience." Psychopathology 50, no. 1:10-54.

Saulton, Aurelie, Heinrich H. Bülthoff, Stephan de la Rosa, and Trevor J. Dodds. 2017. "Cultural Differences in Room Size Perception." PloS One 12, no. 4:e0176115.

Senzaki, Sawa, Takahiko Masuda, and Kristina Nand. 2014. "Holistic versus Analytic Expressions in Artworks: Cross-Cultural Differences and Similarities in Drawings and Collages by Canadian and Japanese School-Age Children." Journal of Cross-Cultural Psychology 45, no. 8:1297-1316.

Shields, James M. 2009. "The Art of Aidagara: Ethics, Aesthetics, and the Quest for an Ontology of Social Existence in Watsuji Tetsurō's Rinrigaku." Asian Philosophy 19, no. 3:265-283.

Spurrett, David, and Stephen Cowley. 2010. "The Extended Infant: UtteranceActivity and Distributed Cognition." In The Extended Mind, edited by Richard Menary, pp. 295-323. Cambridge, MA: MIT Press.

Stevens, Bernard. 2003. "Sur les antécédents de la notion d'«aida». Revue Philosophique de Louvain 101, no. 4:686-706.

van Baaren, Rick B., Rob W. Holland, Kerry Kawakami, and Ad van Knippenberg. 2004. "Mimicry and Prosocial Behavior." Psychological Science 15, no. 1:71-74. 
van den Berg, J. H. 1952. "The Human Body and the Significance of Human Movement: A Phenomenological Study." Philosophy and Phenomenological Research 13, no. 2:159-183.

— 1972. A Different Existence: Principles of Phenomenological Psychopathology. Pittsburgh: Duquesne University Press.

Van Duppen, Zeno. 2017. "The Intersubjective Dimension of Schizophrenia." Philosophy, Psychiatry, and Psychology 24, no. 4:399-418.

Watsuji Tetsurō. 1996. Watsuji Tetsurō's Rinrigaku: Ethics in Japan. Translated by Yamamoto Seisaku and Robert E. Carter. Albany: State University of New York Press.

Waxman, Sandra R., Xiaolan Fu, Brock Ferguson, Kathleen Geraghty, Erin Leddon, Jing Liang, and Min-Fang Zhao. 2016. "How Early Is Infants' Attention to Objects and Actions Shaped by Culture? New Evidence from 24-Month-Olds Raised in the US and China." Frontiers in Psychology 7, no. 7:1-10. doi 10.3389/fpsyg.2016.00097.

Wiltermuth, S. S., and C. Heath. 2009. "Synchrony and Cooperation." Psychological Science 20, no. 1:1-5.

Zahavi, Dan. 2003. Husserl's Phenomenology. Stanford, CA: Stanford University Press.

-. 2008. "Internalism, Externalism, and Transcendental Idealism." Synthese 160, no. 3:355-374.

- 2014. Self and Other: Exploring Subjectivity, Empathy, and Shame. Oxford: Oxford University Press.

—. 2017. Husserl's Legacy: Phenomenology, Metaphysics, and Transcendental Philosophy. Oxford: Oxford University Press. 